\title{
External stenting and disease progression in saphenous vein grafts two years after coronary artery bypass grafting: A multicenter randomized trial
}

\author{
David P. Taggart, MD, ${ }^{\mathrm{a}}$ Yulia Gavrilov, PhD, ${ }^{\mathrm{b}}$ George Krasopoulos, MD, ${ }^{\mathrm{c}}$ Cha Rajakaruna, MD, ${ }^{\mathrm{d}}$ \\ Joseph Zacharias, MD, ${ }^{\mathrm{e}}$ Ravi De Silva, MD, ${ }^{\mathrm{f}}$ Keith M. Channon, MD ${ }^{\mathrm{g}}{ }^{\mathrm{C}}$ Thomas Gehrig, MD, \\ Terrence John Donovan, MD, ${ }^{\mathrm{h}}$ and Ivar Friedrich, MD, ${ }^{\mathrm{h}}$ on behalf of the InVESTigators*
}

\section{ABSTRACT}

Objectives: Little data exist regarding the potential of external stents to mitigate long-term disease progression in saphenous vein grafts. We investigated the effect of external stents on the progression of saphenous vein graft disease.

Methods: A total of 184 patients undergoing isolated coronary artery bypass grafting, using an internal thoracic artery graft and at least 2 additional saphenous vein grafts, were enrolled in 14 European centers. One saphenous vein graft was randomized to an external stent, and 1 nonstented saphenous vein graft served as the control. The primary end point was the saphenous vein graft Fitzgibbon patency scale assessed by angiography, and the secondary end point was saphenous vein graft intimal hyperplasia assessed by intravascular ultrasound in a prespecified subgroup at 2 years.

Results: Angiography was completed in 128 patients and intravascular ultrasound in the entire prespecified cohort $(n=51)$ at 2 years. Overall patency rates were similar between stented and nonstented saphenous vein grafts ( $78.3 \%$ vs $82.2 \%, P=.43$ ). However, the Fitzgibbon patency scale was significantly improved in stented versus nonstented saphenous vein grafts, with Fitzgibbon patency scale I, II, and III rates of $66.7 \%$ versus $54.9 \%, 27.8 \%$ versus $34.3 \%$, and $5.5 \%$ versus $10.8 \%$, respectively (odds ratio, 2.02; $P=.03$ ). Fitzgibbon patency scale was inversely related to saphenous vein graft minimal lumen diameter, with Fitzgibbon patency scale I, II, and III saphenous vein grafts having an average minimal lumen diameter of $2.62 \mathrm{~mm}$, $1.98 \mathrm{~mm}$, and $1.32 \mathrm{~mm}$, respectively $(P<.05)$. Externally stented saphenous vein grafts also showed significant reductions in mean intimal hyperplasia area $(22.5 \% ; P<.001)$ and thickness $(23.5 \% ; P<.001)$.

Conclusions: Two years after coronary artery bypass grafting, external stenting improves Fitzgibbon patency scales of saphenous vein grafts and significantly reduces intimal hyperplasia area and thickness. Whether this will eventually lead to improved long-term patency is still unknown. ( $J$ Thorac Cardiovasc Surg 2022;164:1532-41)

Despite the proposed benefits of multiple arterial grafts, autologous saphenous vein grafts (SVGs) are still the most frequently used $(80 \%)$ bypass conduits in coronary artery bypass grafting (CABG). ${ }^{1}$ SVG failure may be classified into early and late phases. Early SVG failure is largely due to intraoperative technical issues, poor conduit quality or harvesting techniques, or inadequate runoff within the

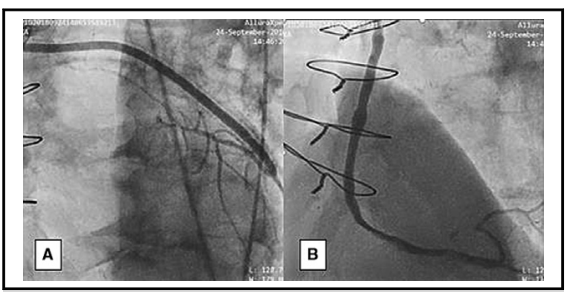

Within-patient comparison of an externally stented SVG to the obtuse marginal branch showing Fitzgibbon I patency (A) and an unsupported SVG to the posterior descending artery with Fitzgibbon III patency (B) 2 years after surgical revascularization.

\section{CENTRAL MESSAGE}

Two years after CABG, external stenting improves Fitzgibbon patency rates of vein grafts and significantly reduces diffuse intimal hyperplasia.

\section{PERSPECTIVE}

Although susceptible to progressive failure, SVGs remain the most frequently used bypass conduits in CABG. Strategies that minimize intimal hyperplasia and SVG structural remodeling postimplantation have the potential to reduce atheroma formation and late SVG failure. Improving SVG longevity should positively affect the clinical outcome of CABG.

See Commentaries on pages 1542 and 1543.
From the a Nuffield Department of Surgical Sciences, University of Oxford, John Radcliffe Hospital, Oxford, United Kingdom; ${ }^{\mathrm{b}}$ TechnoSTAT Ltd, Raanana, Israel; 'Oxford University Hospitals NHS Foundation Trust, Oxford, United Kingdom; ${ }^{\mathrm{d}}$ Department of Cardiothoracic Surgery, University Hospitals Bristol, Bristol,

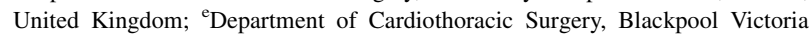

target vessel and, with the exception of overt technical errors, may not be easily amenable to further intervention. ${ }^{2}$

In contrast, late SVG failure may be susceptible to intervention because decades of extensive research have provided deep insights into its pathogenesis. Beginning several days after implantation, SVG disease is dominated by intimal hyperplasia whereby smooth muscle cells
Hospital, Blackpool, United Kingdom; ${ }^{\mathrm{f}}$ Department of Cardiothoracic Surgery, Papworth Hospital, Cambridge, United Kingdom; ${ }^{g}$ Department of Cardiovascular Medicine, University of Oxford, John Radcliffe Hospital, Oxford, United

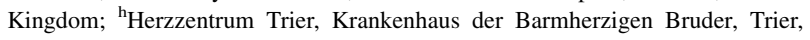
Germany. 

Abbreviations and Acronyms
$\mathrm{CABG}=$ coronary artery bypass grafting
CTA = computed tomography angiography
EEM = external elastic media
$\mathrm{EVH}=$ endoscopic vein harvesting
FPS = Fitzgibbon Patency Scale
ICC = intraclass correlation coefficient
IVUS = intravascular ultrasound
MACCE $=$ major adverse cardiac and cerebrovascular events
MLD = minimal lumen diameter
SVG $=$ saphenous vein graft

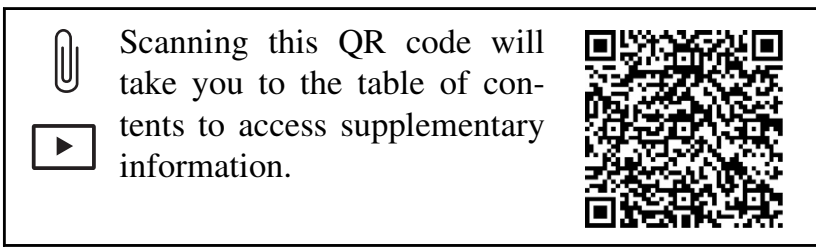

proliferate and migrate to the dysfunctional intima. ${ }^{3}$ Arterial pressures and high circumferential wall stress, allied to lumen irregularities and abnormal flow patterns, are the main contributors to diffuse intimal hyperplasia that eventually predispose the SVG to thrombosis and accelerated atherosclerosis. $^{3,4}$

However, until recently, this pathophysiologic understanding has still not translated into particularly effective therapies. To date, only persistent use of statins and betablockers has been shown to reduce, at least to some extent, the development of intimal hyperplasia in vein grafts. ${ }^{5}$ Surgical approaches that appear to reduce disease progression in SVG include its harvest with a "no touch" technique ${ }^{6}$

\footnotetext{
* Umberto Benedetto, MD, ${ }^{\mathrm{d}}$ Hunaid Vohra, MD,${ }^{\mathrm{d}}$ Mohamad Nidal Bittar, MD,${ }^{\mathrm{e}}$ Amal Bose, MD,${ }^{\mathrm{e}}$ Marius Berman, $\mathrm{MD},{ }^{\mathrm{f}}$ Rajesh Kharbanda, $\mathrm{MD},{ }^{\mathrm{g}}$ Alexandros Paraforos, $\mathrm{MD},{ }^{\mathrm{h}}$ Leonid, Ladyshenskij, MD, ${ }^{\mathrm{i}}$ Nikolaos Bonaros, MD, ${ }^{\mathrm{j}}$ Thomas Schachner, MD, ${ }^{\mathrm{j}}$ Sigrid Sandner, MD, ${ }^{\mathrm{k}}$ Philipp Angleitner, MD,${ }^{\mathrm{k}}$ Gil Bolotin, MD, ${ }^{\mathrm{l}}$ Stephan Jacobs, MD, ${ }^{\mathrm{m}}$ Matthias Thielmann, MD, ${ }^{\mathrm{n}}$ Daniel Wendt, MD, ${ }^{\mathrm{n}}$ Yeong-Hoon Choi, MD, ${ }^{\mathrm{o}, \mathrm{p}, \mathrm{q}, \mathrm{r}}$ Oliver Liakopoulos, MD, ${ }^{\mathrm{o}, \mathrm{p}, \mathrm{q}, \mathrm{r}}$ Sunil Ohri, MD, ${ }^{\mathrm{s}}$ and Alexander Lipey, MD ${ }^{t}$. ${ }^{\mathrm{d}}$ Department of Cardiothoracic Surgery, University Hospitals Bristol, Bristol, United Kingdom; ' Department of Cardiothoracic Surgery, Blackpool Victoria Hospital, Blackpool, United Kingdom; ${ }^{\mathrm{f}}$ Department of Cardiothoracic Surgery, Papworth Hospital, Cambridge, United Kingdom; ${ }^{\mathrm{g}}$ Department of Cardiovascular Medicine, University of Oxford, John Radcliffe Hospital, Oxford, United Kingdom; ' ${ }^{\mathrm{h}}$ Herzzentrum Trier, Krankenhaus der Barmherzigen Bruder,

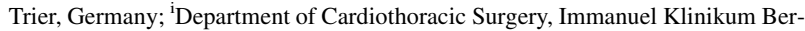
nau Herzzentrum Brandenburg, Brandenburg, Germany; ${ }^{\mathrm{j}}$ Department of Cardiothoracic Surgery, Medical University of Innsbruck, Innsbruck, Austria; ${ }^{\mathrm{k}}$ Department of Cardiothoracic Surgery, Medizinische Universität Wien, Vienna,

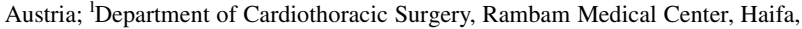
Israel; ${ }^{\mathrm{m}}$ Department of Cardiothoracic Surgery, German Heart Centre Berlin, Berlin, Germany; ${ }^{\mathrm{n}}$ Department of Cardiothoracic Surgery, West-German Heart and Vascular Center Essen, University Hospital Essen, Essen, Germany; ${ }^{\circ}$ Department of Cardiac Surgery, Kerckhoff Heart Center, Bad Nauheim, Germany; ${ }^{\mathrm{P} J u s t u s-L i e-~}$ big-University Gießen, Campus Kerckhoff, Bad Nauheim, Germany; ${ }^{\mathrm{q}}$ German
}

or the use of the SVG as a composite graft from the internal thoracic artery. ${ }^{7}$

Since Parsonnet and colleagues ${ }^{8}$ initially described the concept of external stenting of vein grafts in an animal model in 1963, the potential benefit of the technique has been described extensively in preclinical research. ${ }^{9}$ However, clinical trials with first-generation external stenting technologies provided disappointing results, with early SVG patency of $0 \%$ to $28 \%$ at 6 to 9 months. ${ }^{10,11}$ Recent trials using current-generation, biomechanically improved external stents have provided more promising results with early SVG patency ranging from $86 \%$ to $100 \%$. $^{12,13}$

From the outset, it is crucial to appreciate that external stenting cannot mitigate many of the causes of early vein graft failure but is instead designed to minimize disease progression in the SVG over the longer term. Indeed, small previous studies of up to 30 patients using intravascular ultrasound (IVUS) and optical coherence tomography produced profound pathophysiologic insights into the biomechanical benefits of external stenting by demonstrating significant reductions in lumen irregularities, intimal hyperplasia, thrombus formation, and oscillatory shear stress in SVG at 1 and 4.5 years after CABG. ${ }^{14-17}$

The current trial, Venous External Support Trial III (VEST III), aimed to validate previous observations regarding the effects of external stenting in a larger cohort of patients $(\mathrm{n}=184)$ and to provide additional insights regarding their mechanism of action 2 years after $\mathrm{CABG}$.

\section{MATERIALS AND METHODS \\ Patients and Design}

VEST III (NCT02511834) investigated the performance of the CE marked VEST external stent (Vascular Graft Solutions Ltd, Tel Aviv, Israel) over 2 years in a prospective, within-patient, controlled, randomized, multicenter international trial. The study was conducted in accordance with the principles of the Declaration of Helsinki and all applicable regulations. The protocol was approved by the independent institutional review

Center for Cardiovascular Research (DZHK), Partner Site Rhine Main, Frankfurt/Main, Germany; ${ }^{r}$ Department of Cardiothoracic Surgery, Uniklinik Köln, Germany; ${ }^{\mathrm{s}}$ Department of Cardiothoracic Surgery, University Hospital Southampton, Southampton, United Kingdom; and 'Department of Cardiothoracic Surgery, Sheba Medical Center, Ramat Gan, Israel.

The VEST III Study was funded by Vascular Graft Solutions (Israel). The investigators had full academic freedom.

Clinical Trial Registry Number: NCT02511834. Institutional Review Board Information: UK - REC 15/SC/0311, July 9, 2015, Germany - CIV-15-04-013504, September 8, 2015, Austria - Vienna EC 1330/2015, August 11, 2015, Innsbruck EC AN2016-0036 359/4.11, August 8, 2016, Israel - Rambam 0244-15-RMB, August 12, 2015, Sheba 2357-15-SMC, December 17, 2015.

Received for publication Nov 9, 2020; revisions received March 28, 2021; accepted for publication March 29, 2021; available ahead of print April 21, 2021.

Address for reprints: Ivar Friedrich, MD, Herzzentrum Trier, Nordallee 1, 54292 Trier, Germany (E-mail: i.friedrich@bk-trier.de). 0022-5223

Copyright (C) 2021 The Authors. Published by Elsevier Inc. on behalf of The American Association for Thoracic Surgery. This is an open access article under the CC BY-NC-ND license (http://creativecommons.org/licenses/by-nc-nd/4.0/). https://doi.org/10.1016/j.jtcvs.2021.03.120 


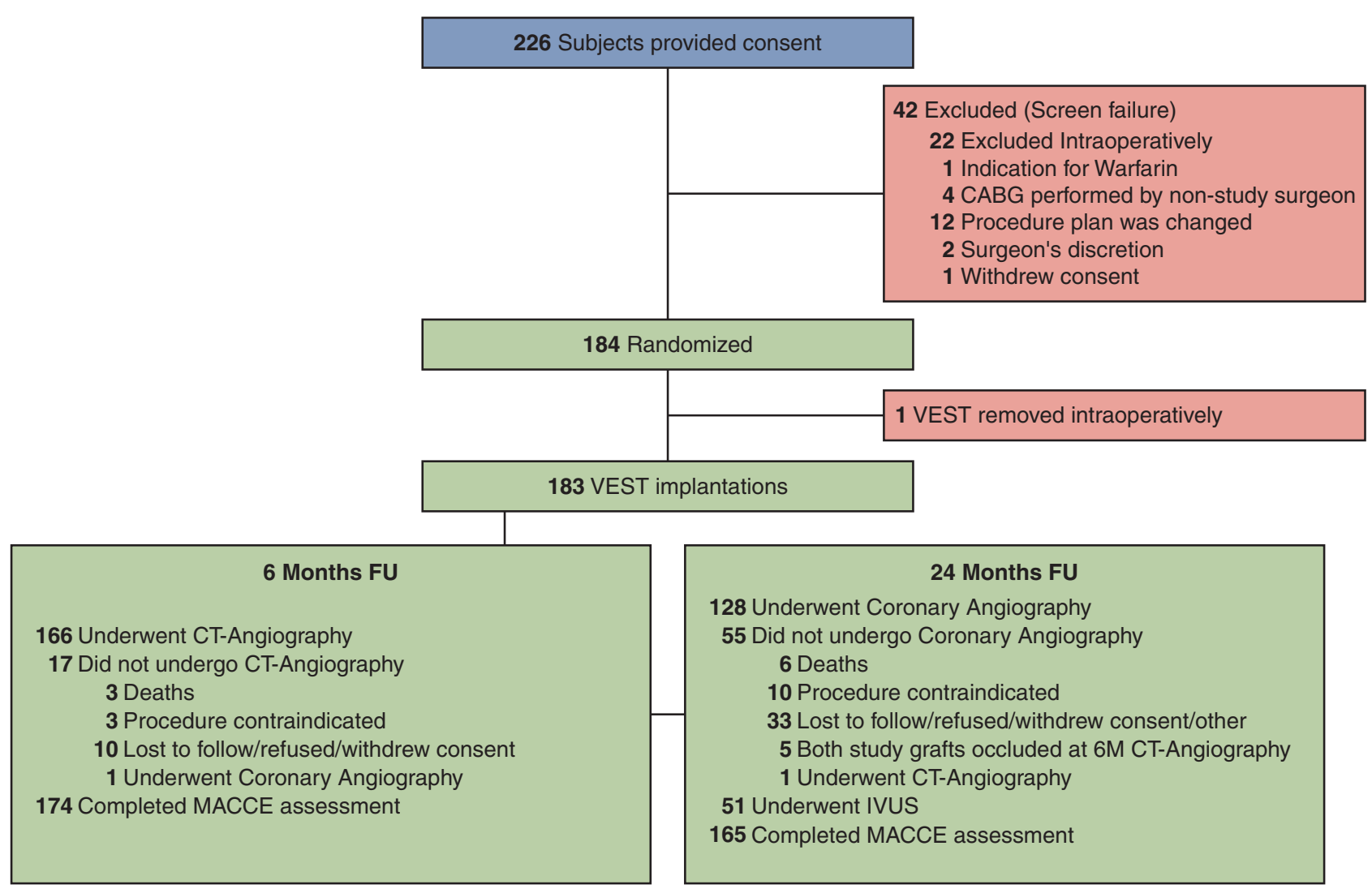

FIGURE 1. CONSORT diagram of study enrollment and follow-up. IVUS, Intravascular ultrasound; MACCE, major cardiac and cerebrovascular events.

board or ethics committee responsible for each participating site (UK REC 15/SC/0311, July 9, 2015, Germany - CIV-15-04-013504, September 8, 2015, Austria - Vienna EC 1330/2015, August 11, 2015, Innsbruck EC AN2016-0036 359/4.11, August 8, 2016, Israel - Rambam 0244-15RMB, August 12, 2015, Sheba 2357-15-SMC, December 17, 2015), and informed written consent was obtained from all patients.

Patients were eligible if they required an internal thoracic artery graft to the left anterior descending coronary artery in addition to 2 or more aortocoronary SVGs to the right and left coronary territories. Further inclusion criteria included an adequate distal vascular bed and noncalcified coronary artery target sites $1.5 \mathrm{~mm}$ in diameter or greater. After completion of all distal anastomoses, each patient was randomized to receive 1 external stent applied to $1 \mathrm{SVG}$, and an additional nonstented SVG served as control. In cases in which 3 vein grafts were used, 2 stages of randomization were performed to randomize first the stented graft and then the control SVG.

The primary end point was Fitzgibbon patency scale (FPS) defined by angiography. ${ }^{18}$ The secondary end point was intimal hyperplasia area as assessed by IVUS. The primary safety end point evaluated major adverse cardiac and cerebrovascular events (MACCE). The CONSORT diagram is presented in Figure 1. Enrollment was completed on schedule with slightly fewer patients than originally planned (184 vs 200). The trial was completed in May 2019, and the database was locked on October 3, 2019 (Figure 2).

\section{Procedure and Follow-up}

Vein grafts were harvested using both open and endoscopic techniques according to the individual site standard of care. Side branches were ligated with ties or sutures. All procedures were performed with cardiopulmonary bypass. To avoid potential bias, randomization of vein grafts to be treated with external stents or to serve as controls was performed using sealed envelopes only after intraoperative eligibility criteria of target vessel quality was met and subsequent to completion of all distal anastomoses.

The appropriate device model was selected on the basis of SVG length and diameter. The SVG was threaded through the device before performance of the proximal anastomosis and manually expanded over the entire SVG. No further fixation of the device to the vein graft was performed. When available, transit time flow measurements were performed on venous and arterial bypass grafts to identify possible technical shortcomings in the operating room (Video 1). All patients were prescribed statins, betablockers, and aspirin as per practice guidelines.

Computed tomography angiography (CTA) was performed 6 months after CABG to detect early SVG occlusions. Two years after CABG, patients with at least 1 patent study graft based on CTA findings underwent contrast coronary angiography. In addition, a preplanned subgroup of patients in which both study grafts were patent based on the 6-month CTA underwent IVUS assessment for intimal hyperplasia. These patients were examined on an all-comer basis in centers that possessed the technical capability to perform the procedure according to the protocol until the predetermined number of studies had been carried out. Because angiography and IVUS were performed in the same session, there was no potential for selection bias on the basis of the angiographic FPS.

\section{Angiography and Intravascular Ultrasound}

All angiograms and IVUS images were analyzed by an independent Intravascular Imaging Core Laboratory at the Mount Sinai Hospital (New York, NY) by 2 independent observers. Coronary angiograms were acquired in at least 4 vertical planes. Initial assessment was performed to determine graft patency. The FPS classification of intimal irregularity 
VEST III Trial design, endpoints and main findings 2 years following coronary artery bypass grafting

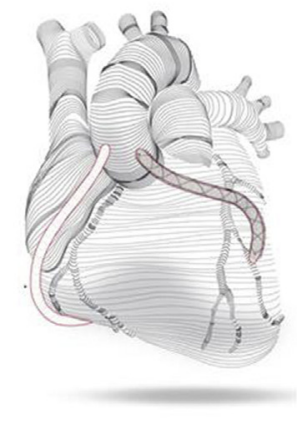

Basic design: In 184 patients undergoing isolated multivessel $\mathrm{CABG}$, one SVG was randomized intra-operatively to an external stent while one non-stented SVG served as the control
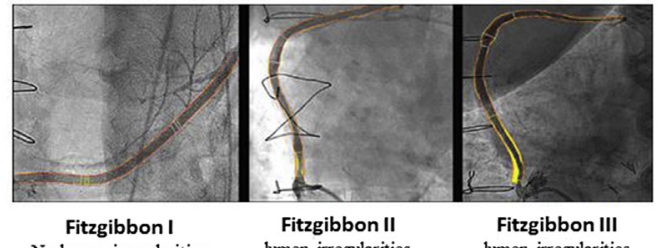

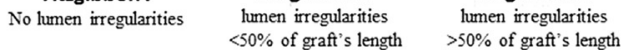
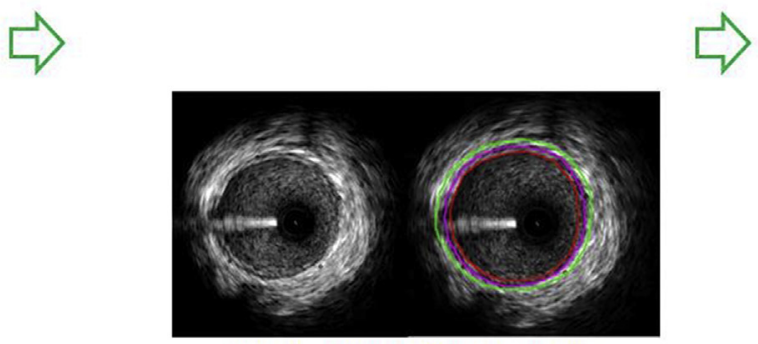

IVUS assessment of intimal hyperplasia
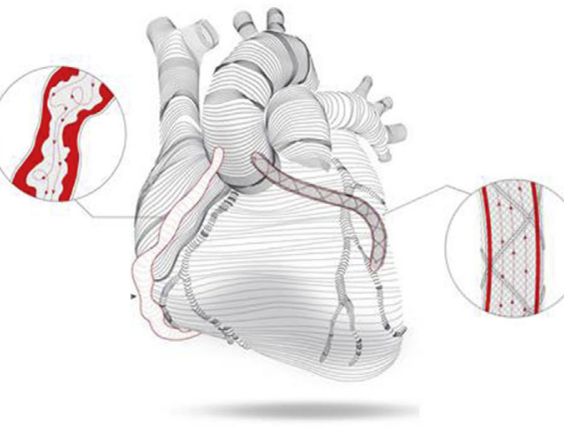

Main Findings: Two years after $\mathrm{CABG}$, external stenting significantly improves Fitzoibbon patency scales of SVG and reduces intimal hyperplasia area and thickness.

Abbreviations: $\mathrm{CABG}=$ coronary artery bypass grafting, $\mathrm{SVG}=$ saphenous vein graft, IVUS=intravascular ultrasound
Study endpoints: The primary endpoint was SVG Fitzgibbon patency scale assessed by angiography and the secondary endpoin was SVG intimal hyperplasia assessed by intravascular ultrasound in a pre-specified subgroup $(\mathrm{N}=51)$ at 2 years. Both imaging endpoints were assessed by an independent core lab.

FIGURE 2. Left: Basic design of the study. Center: Primary and secondary end points. Right: Main findings.

(which should not be confused with the flow-based ABO Fitzgibbon classification) was assessed for all patent study grafts by 4-plane angiography. ${ }^{18}$ All patent study SVGs were graded from the worst appearance in 4-plane views (Figure 3) as perfectly patent SVG: smooth graft outline with no intimal irregularities; intimal irregularities of less than $50 \%$ of estimated intimal surface; and intimal irregularities of greater than $50 \%$ of estimated intimal surface.

Quantitative coronary angiography analysis was performed using QAngio XA software (Medis, Leiden, The Netherlands) for each patent SVG. Minimal, maximal, and mean diameters were measured for each SVG and averaged for every 5-mm segment using an angiographic plane and frame showing the worst appearance. Ectasia was defined as a segmental dilation more than $50 \%$ compared with the normal adjacent segments.

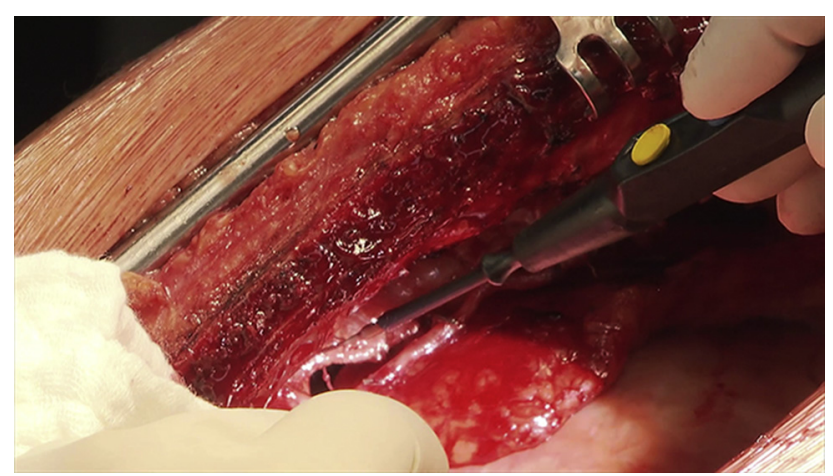

VIDEO 1. The rationale for external vein graft stenting is explained, and the implantation technique for the VEST is demonstrated under actual operating room conditions. Video available at: https://www.jtcvs.org/ article/S0022-5223(21)00723-6/fulltext.
IVUS imaging of the entire lengths of both study grafts, stented and nonstented, was performed on a preplanned subgroup of 51 patients at 6 study sites that possessed the required expertise and equipment. Imaging was acquired using a motorized pullback 40 to $45 \mathrm{MHz}$ IVUS catheter. The IVUS catheter was advanced beyond the distal anastomosis and then pulled back using a motorized system at a rate of $0.5 \mathrm{~mm} / \mathrm{s}$ to the aortoostial junction and repeated several times for each graft. IVUS image analyses were performed by experienced analysts blinded to angiographic analysis using QIvus software (Medis), according to published consensus document definitions. ${ }^{19}$ Quantitative IVUS measurements included measurements of the external elastic media (EEM) area and lumen crosssectional areas, EEM, and lumen diameters at $10-\mathrm{mm}$ intervals along the graft from the distal to proximal anastomosis (Figure 4). Manual tracings were performed on frames with the intimal hyperplasia layer clearly visualized and without image artifacts. The intimal hyperplasia area was calculated as the EEM area minus the lumen area. The average intimal-medial thickness was calculated by subtracting the average lumen diameter from the average EEM diameter and dividing by 2 .

To assess the intervariability of quantitative coronary angiography and IVUS measurements, 30 angiograms and 40 IVUS cross-sectional images were randomly selected from the study database and analyzed by the 2 independent observers that evaluated the primary and secondary end points. To evaluate the intraobserver variability, 1 of the observers repeated the same analyses 1 month later. Intraobserver and interobserver agreement for quantitative measurements were assessed by intraclass correlation coefficient (ICC) based on the random-effects analysis of variance model. Cohen's kappa was used for categorical variables. The agreement on Fitzgibbon grading was excellent $(\mathrm{k}=0.92)$. Likewise, interobserver reproducibility was high for IVUS intimal hyperplasia area (ICC $=0.94 ; 95 \%$ confidence interval, 0.86-0.97) and thickness (ICC $=0.96 ; 95 \%$ confidence interval, 0.90-0.98). 

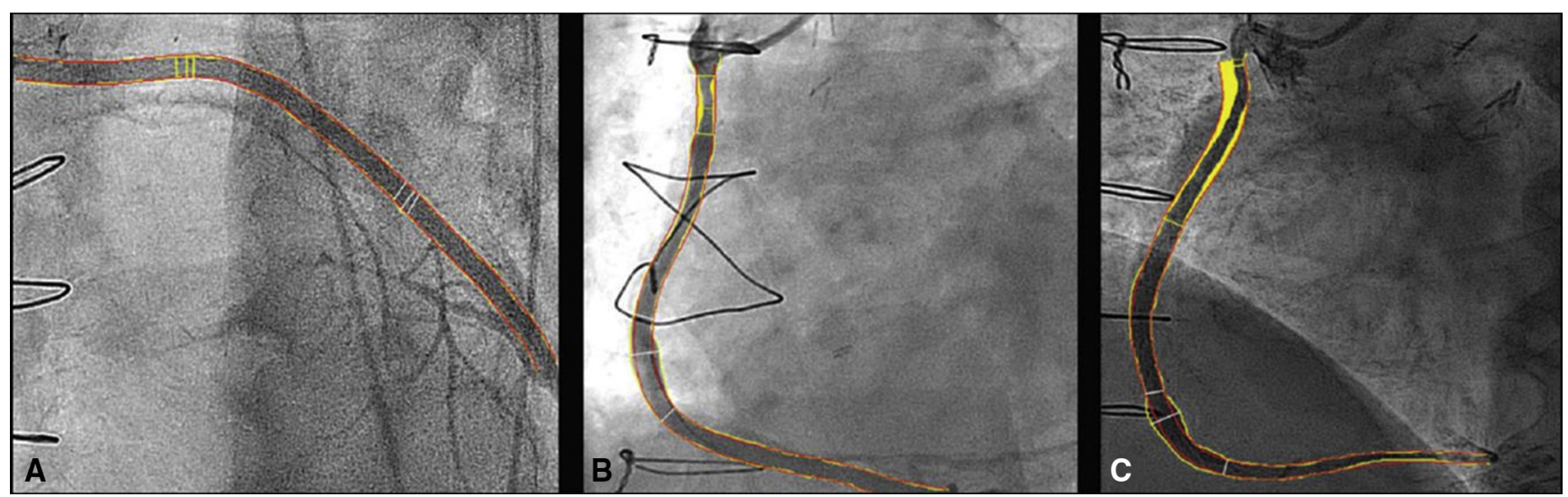

FIGURE 3. The angiographic appearance of the Fitzgibbon classification: A, Fitzgibbon I patency (perfect patency) with no lumen irregularities. B, Fitzgibbon II patency with lumen irregularities that involve less than $50 \%$ of SVG length. C, Fitzgibbon III patency with lumen irregularities that involve more than $50 \%$ of SVG length. $S V G$, Saphenous vein graft.

\section{Statistical Analysis}

Sample size was determined using the following assumptions previously reported in the literature: Fitzgibbon I patency scale (perfect patency) rate in the control group at 2 years is $50 \% .{ }^{16,20}$ Treatment effect of the VEST external stent is $25 \%$. $^{16}$

In addition, it was assumed that the intersubject correlation between intimal area measured in supported and unsupported grafts is 0.50 . Assuming a dropout rate of approximately $20 \%$, it was planned to recruit 200 patients between October 2015 and January 2017 that would provide $90 \%$ power to demonstrate superiority in the FPS. Analysis was performed by an independent statistician according to statistical analysis plan (TechnoSTAT, Raanana, Israel). This plan later underwent minor revision to harmonize it with the specifications of the Cardiothoracic Surgical Trials Network PIVOTAL Trial (NCT 03209609) and to extend analysis of FPS I scores to include FPS II and III scores. The revised statistical analysis plan, which was completed before database lock and data analysis, is included in Appendix E1.

To compare the full spectrum of SVG disease progression (FPS I/II/III), primary analysis of Fitzgibbon classification was performed using an ordinal multinomial regression with patient random effect. Analysis of occlusion was carried out using logistic regression with patient random effect for comparison between the 2 graft groups. Instances of occlusion at 6 months, for which there was no 24-month follow-up, were included as occlusion at 24 months. Odds ratios for each of these end points were calculated directly from their respective regression results.

The IVUS analysis set consisted of all patients with intimal hyperplasia measurements at 2 years for at least 1 study graft or missing IVUS data due to SVG stenosis or occlusion that had developed between 6 to 24 months. Intimal hyperplasia and lumen diameter were analyzed using a mixed linear model with repeated measurements per subject for stented and nonstented grafts. Values of intimal hyperplasia and lumen diameter at 24 months that were missing due to SVG stenosis or occlusion were imputed as worst-case values, that is, 80th percentile of the group for intimal hyperplasia and 20th percentile of the group for lumen diameter. Any values missing because of nonclinical reasons were not imputed. Estimate of MACCE and its component rates was performed using 95\% exact binomial confidence intervals. All statistical analyses were carried out using SAS software version 9.4 (SAS Institute Inc, Cary, NC). A detailed description of the statistical methodology is available in Appendix E1.

\section{RESULTS \\ Patients, Procedure, and Follow-up}

Of the 226 patients who gave informed consent, 42 did not satisfy the screening criteria and 184 were enrolled and randomized. An external stent was implanted in 183

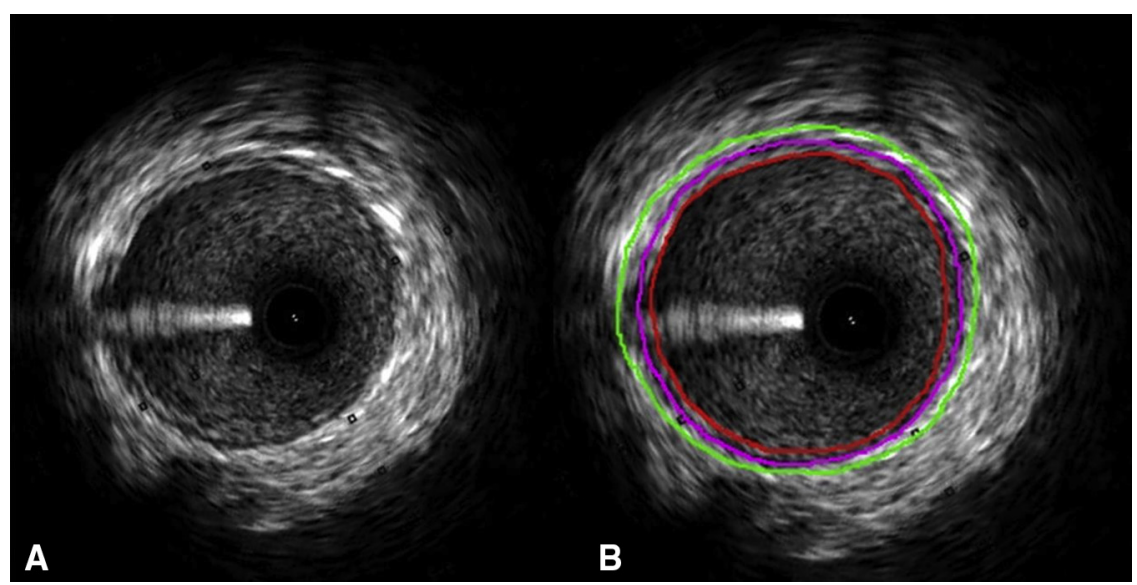

FIGURE 4. Intravascular analysis of an externally stented SVG segment 2 years after surgery without (A) and with (B) highlighting of the lumen (red), external elastic membrane (purple), and external stent (green). 
TABLE 1. Demographics and baseline data

\begin{tabular}{|c|c|}
\hline Characteristic & Mean $( \pm$ SD) or $n(\%)$ \\
\hline Sample size & $\mathrm{N}=183$ \\
\hline Age (y) & $66.6 \pm 7.9$ \\
\hline Male & $154(84.2 \%)$ \\
\hline Body mass index $\left(\mathrm{kg} / \mathrm{m}^{2}\right)$ & $28.6 \pm 4.4$ \\
\hline $\begin{array}{l}\text { Smoking status } \\
\text { Current } \\
\text { Ex-smoker (>6 mo) } \\
\text { Never } \\
\text { Unknown }\end{array}$ & $\begin{array}{l}48(26.2 \%) \\
70(38.3 \%) \\
50(27.3 \%) \\
15(8.2 \%)\end{array}$ \\
\hline $\begin{array}{l}\text { Diabetes } \\
\text { IDDM } \\
\text { NIDDM } \\
\text { No history }\end{array}$ & $\begin{array}{r}25(13.7 \%) \\
29(15.8 \%) \\
129(70.5 \%)\end{array}$ \\
\hline Hypertension & $168(91.8 \%)$ \\
\hline Hyperlipidemia & $164(89.6 \%)$ \\
\hline Documented hypercoagulable state & $2(1.1 \%)$ \\
\hline Diffuse peripheral vascular disease & $26(14.2 \%)$ \\
\hline Prior cardiovascular surgery & $6(3.3 \%)$ \\
\hline Prior stroke (nondebilitating) & $3(1.6 \%)$ \\
\hline Indication for Warfarin & $1(0.5 \%)$ \\
\hline Chronic obstructive pulmonary disease & $23(12.6 \%)$ \\
\hline Unknown & $1(0.5 \%)$ \\
\hline Prior myocardial infarction & $58(31.7 \%)$ \\
\hline Unknown & $2(1.1 \%)$ \\
\hline Prior PCI & $48(26.2 \%)$ \\
\hline $\begin{array}{l}\text { New York Heart Association Class } \\
\text { I } \\
\text { II } \\
\text { III } \\
\text { IV } \\
\text { Unknown }\end{array}$ & $\begin{array}{c}28(15.3 \%) \\
91(49.7 \%) \\
55(30.1 \%) \\
4(2.2 \%) \\
5(2.7 \%)\end{array}$ \\
\hline $\begin{array}{l}\text { Canadian Cardiovascular Society Class } \\
\text { I } \\
\text { II } \\
\text { III } \\
\text { IV } \\
\text { Unknown }\end{array}$ & $\begin{array}{l}18(9.8 \%) \\
77(42.1 \%) \\
54(29.5 \%) \\
14(7.7) \\
20(10.9 \%)\end{array}$ \\
\hline $\begin{array}{l}\text { LVEF }(\%) \\
\quad<35 \\
35-55 \\
>55 \\
\text { Unknown }\end{array}$ & $\begin{array}{c}5(2.7 \%) \\
78(42.6 \%) \\
89(48.6 \%) \\
11(6 \%)\end{array}$ \\
\hline Creatinine $(\mu \mathrm{mol} / \mathrm{L})$ & $88.6 \pm 21.1$ \\
\hline Preoperative logistic euroSCORE (\%) & $2.5 \pm 2.6$ \\
\hline Unknown euroSCORE (\%) & $20(11 \%)$ \\
\hline
\end{tabular}

Baseline characteristics of the entire study population are shown. $S D$, Standard deviation; IDDM, insulin-dependent diabetes mellitus; NIDDM, noninsulin-dependent diabetes mellitus; PCI, percutaneous coronary intervention; euroSCORE, European System for Cardiac Operative Risk Evaluation.
TABLE 2. Procedure and perioperative data

\begin{tabular}{|c|c|}
\hline Characteristic $(n=183)$ & Mean $( \pm$ SD) or $\mathbf{n}(\%)$ \\
\hline \multicolumn{2}{|l|}{ Surgery scheduling } \\
\hline Elective & $159(86.9 \%)$ \\
\hline Urgent & $24(13.1 \%)$ \\
\hline Emergency & 0 \\
\hline Surgery duration (min) & $237.4 \pm 51.4$ \\
\hline Pump duration (min) & $97.7 \pm 26.8$ \\
\hline Clamp duration (min) & $60.4 \pm 21.1$ \\
\hline \multicolumn{2}{|l|}{ SVG harvesting technique } \\
\hline Direct vision (open) & $118(64.5 \%)$ \\
\hline Endoscopic & $57(31.1 \%)$ \\
\hline Bridge & $5(2.7 \%)$ \\
\hline Other & $3(1.6 \%)$ \\
\hline \multicolumn{2}{|l|}{ Vein origin } \\
\hline Above the knee & $36(19.7 \%)$ \\
\hline Below the knee & $28(15.3 \%)$ \\
\hline Both above and below the knee & $119(65 \%)$ \\
\hline \multicolumn{2}{|l|}{ Vein varicosity } \\
\hline None & $146(79.8 \%)$ \\
\hline Mild & $33(18 \%)$ \\
\hline Moderate & $4(2.2 \%)$ \\
\hline Severe & 0 \\
\hline Total No. of grafts (SVGs + arteries) & $597(100 \%)$ \\
\hline Study SVGs (VEST and control) & $366(61.3 \%)$ \\
\hline Additional/other SVGs & $32(5.4 \%)$ \\
\hline ITA-LAD & $182(30.5 \%)$ \\
\hline Second arterial graft & $17(2.8 \%)$ \\
\hline \multicolumn{2}{|l|}{ No. of grafts per patient } \\
\hline 3 & $138(75.4 \%)$ \\
\hline 4 & $42(23 \%)$ \\
\hline 5 & $3(1.6 \%)$ \\
\hline Postoperative hospitalization duration (d) & $9.34 \pm 5.18$ \\
\hline
\end{tabular}

patients; 1 device was removed intraoperatively because of technical failure. Demographic and baseline characteristics are presented in Table 1 .

A comparable grafting pattern was observed in both the stented and nonstented groups. Within the left coronary territory, there was a similar distribution of stented and nonstented SVGs to the obtuse marginal (60 vs 61), diagonal (14 vs 10), circumflex (11 vs 11), and intermediate (9 vs 7) coronary arteries, respectively. The right coronary territory was bypassed with 89 stented versus 94 nonstented SVGs. Transit time flow measurements and pulsatility index were assessed in 129 patients, and 2 grafts were revised ( 1 stented and 1 not stented) in 1 patient before chest closure (Table 2).

As shown in Table 3, baseline native coronary parameters that may contribute to SVG patency and the development of intimal hyperplasia did not differ between the stented and 
TABLE 3. Baseline grafting parameters of study grafts

\begin{tabular}{|c|c|c|c|}
\hline Characteristic & VEST mean $(95 \%$ CL) & Control mean $(95 \%$ CL) & $P$ value \\
\hline Host coronary artery diameter (mm) & $1.76(1.71-1.80)(\mathrm{n}=182)$ & $1.75(1.70-1.79)(\mathrm{n}=183)$ & .693 \\
\hline Graft length $(\mathrm{cm})$ & $15.59(15.16-16.02)(n=183)$ & $15.70(15.27-16.13)(\mathrm{n}=180)$ & .723 \\
\hline Systolic pressure at TTFM $(\mathrm{mm} \mathrm{Hg})$ & $101.57(98.65-104.49)(\mathrm{n}=121)$ & $101.19(98.26-104.11)(\mathrm{n}=120)$ & .586 \\
\hline Final TTFM flow (mL/min) & $52.09(46.68-57.49)(\mathrm{n}=129)$ & $54.44(49.03-59.84)(\mathrm{n}=129)$ & .447 \\
\hline Final TTFM pulsatility index & $2.28(1.82-2.73)(\mathrm{n}=119)$ & $2.54(2.08-2.99)(\mathrm{n}=119)$ & .073 \\
\hline \multicolumn{4}{|l|}{ Coronary target vessels $\mathrm{N}(\%)$} \\
\hline Circumflex & $11(6.0)$ & $11(6.0)$ & 1.000 \\
\hline Obtuse marginal & $60(32.8)$ & $61(33.3)$ & .912 \\
\hline Diagonal & $14(7.7)$ & $10(5.5)$ & .401 \\
\hline Intermediate & $9(4.9)$ & $7(3.8)$ & .611 \\
\hline $\mathrm{RCA}$ & $31(16.9)$ & $29(15.8)$ & .778 \\
\hline PDA & $58(31.7)$ & $65(35.5)$ & .440 \\
\hline
\end{tabular}

Baseline graft and target vessel data compared between externally stented and control saphenous venous grafts. VEST, Venous external stent; $C L$, confidence level; $T T F M$, transit time flow measurement; $R C A$, right coronary artery; $P D A$, posterior descending artery.

nonstented groups. A total of 166 patients $(90.7 \%)$ underwent CTA 6 months post-CABG. Two years after the index procedure, 128 patients ( $80 \%$ of eligible patients) were assessed by contrast angiography and 51 patients (96 SVG) underwent IVUS imaging of the study grafts.

\section{Angiography and Intravascular Ultrasound}

SVG patency at 2 years was not significantly different between the stented and nonstented groups $(78.3 \%$ vs $82.2 \%$, respectively, $P=.432$ ). In both the stented and nonstented groups, SVG occlusion rates were similar in the left $(23.6 \%$ stented vs $20 \%$ nonstented $)$ and right ( $19.7 \%$ stented vs $15.7 \%$ nonstented) coronary territories. Intraoperative flow rates and pulsatility index did not differ between the subsequently early ( 6 months) occluded $(49.7 \pm 32.1 \mathrm{~mL} / \mathrm{min}, 2.4 \pm 0.7$, respectively, $\mathrm{N}=24)$ and patent SVG $(53.8 \pm 30.9 \mathrm{~mL} / \mathrm{min}, 2.4 \pm 2.7$, respectively, $\mathrm{N}=207)$.

As shown in Table 4, the primary end point analysis demonstrated that patent grafts, as graded by the Fitzgibbon scale, were significantly less likely to have intimal irregularities in stented versus nonstented grafts (odds ratio, 2.02; $P=.03$ ). Likewise, there was less SVG ectasia in stented versus nonstented grafts $(4.8 \%$ vs $11.3 \%$, respectively, $P=.078)$. The Fitzgibbon scale was inversely related to SVG minimal lumen diameter (MLD) with Fitzgibbon I, II, and III SVG having an average MLD of $2.62 \mathrm{~mm}$, $1.98 \mathrm{~mm}$, and $1.32 \mathrm{~mm}$, respectively $(P<.05)$.

TABLE 4. Angiographic findings 2 years after coronary artery bypass grafting

\begin{tabular}{|c|c|c|c|}
\hline & VEST N $=138 \%$ (n) & Control $N=135 \%$ (n) & $P$ value \\
\hline Vein graft occlusion & $21.7 \%(30)$ & $17.8 \%(24)$ & $.4315(\mathrm{OR}, 1.278)$ \\
\hline Vein graft patency & $78.3 \%(108)$ & $82.2 \%(111)$ & \\
\hline Fitzgibbon I & $66.7 \%(72)$ & $54.9 \%(61)$ & $.031(\mathrm{OR}, 2.02)$ \\
\hline Fitzgibbon II & $27.8 \%(30)$ & $34.3 \%(38)$ & \\
\hline Fitzgibbon III & $5.5 \%(6)$ & $10.8 \%(12)$ & \\
\hline \multicolumn{4}{|c|}{ Correlation analysis of QCA MLD vs Fitzgibbon (I, II, III) } \\
\hline Fitzgibbon classification & & MLD (mm) & $P$ value \\
\hline I & & $2.62(2.41,2.82)$ & \\
\hline II & & $1.98(1.66,2.31)$ & \\
\hline III & & $1.31(0.69,1.92)$ & \\
\hline I vs II & & $-0.63(-1.00,-0.27)$ & .001 \\
\hline I vs III & & $-1.31(-1.95,-0.67)$ & $<.001$ \\
\hline II vs III & & $-0.68(-0.00,-1.36)$ & .051 \\
\hline
\end{tabular}


TABLE 5. Intravascular ultrasound-based measurements 2 years after coronary artery bypass grafting

\begin{tabular}{|c|c|c|c|c|}
\hline & VEST $N=50$ Mean $(95 \%$ CL $)$ & Control $N=46$ Mean $(95 \%$ CL $)$ & $\%$ Difference & $P$ value \\
\hline $\mathrm{IH}$ area $\left[\mathrm{mm}^{2}\right]$ & $3.07(2.70,3.44)$ & $3.96(3.58,4.34)$ & $-22.5 \%$ & $<.001$ \\
\hline IH thickness [mm] & $0.26(0.23,0.29)$ & $0.34(0.31,0.37)$ & $-23.5 \%$ & $<.001$ \\
\hline IVUS average lumen diameter [mm] & $3.51(3.32,3.69)$ & $3.34(3.14,3.53)$ & $5 \%$ & .106 \\
\hline \multicolumn{5}{|l|}{ IVUS findings for Fitzgibbon } \\
\hline $\mathrm{IH}$ area $\left[\mathrm{mm}^{2}\right]$ & $2.75(2.40,3.09)$ & $3.86(3.42,4.29)$ & $-28.7 \%$ & $<.001$ \\
\hline IH thickness $[\mathrm{mm}]$ & $0.23(0.20,0.25)$ & $0.31(0.28,0.34)$ & $-25.8 \%$ & $<.001$ \\
\hline IVUS average lumen diameter [mm] & $3.57(3.36,3.77)$ & $3.66(3.40,3.91)$ & $-2.5 \%$ & .577 \\
\hline \multicolumn{3}{|c|}{ Correlation between IH thickness and minimal lumen diameter and lumen area } & Coefficient & $P$ value \\
\hline \multicolumn{3}{|c|}{ IH thickness vs IVUS minimal lumen diameter } & -0.28 & .01 \\
\hline \multicolumn{3}{|l|}{ IH thickness vs IVUS lumen area } & -0.24 & .02 \\
\hline \multicolumn{3}{|c|}{ IH thickness vs QCA minimal lumen diameter } & -0.27 & .02 \\
\hline
\end{tabular}

The upper portion shows the differences in intimal thickness, intimal area, and average lumen diameter between all SVGs the VEST and control groups at 2 years as measured by IVUS. The central portion shows this comparison exclusively for Fitzgibbon grade I grafts. The lower portion shows the correlation between intimal thickness and the minimal lumen diameter and area as measured by IVUS, as well as the correlation between intimal thickness and minimal lumen diameter as measured by qualitative coronary angiography. Between-group comparison of IVUS findings was performed using a mixed model with random subject effects. Correlation coefficients and $P$ values were calculated using Pearson correlation. $C L$, Confidence level; $I H$, intimal hyperplasia, $I V U S$, intravascular ultrasound; $S V G$, saphenous vein graft; $Q C A$, quantitative coronary angiography; $C A B G$, coronary artery bypass grafting.

As shown in Table 5, intimal hyperplasia area and thickness were both significantly reduced in the stented compared with the nonstented grafts $(-22.5 \%$ and $-23.5 \%$, respectively, $P<.001)$. When analyzing only Fitzgibbon I SVG, differences in intimal hyperplasia area and thickness between stented and nonstented groups remained highly significant $(-28.7 \%$ and $-25.8 \%$, respectively, $P<.001$ ). A significant correlation among intimal hyperplasia thickness, MLD, and lumen area was also observed.

For all groups of randomized and additional vein grafts $(\mathrm{n}=294)$, patency at 2 years was significantly better when veins were harvested by use of an open $(n=193)$ compared with an endoscopic $(\mathrm{n}=101)$ surgical technique $(88.6 \%$ vs $65.3 \%, P<.001)$. The effect of harvesting technique on SVG patency was observed in both the stented (87.8\% open vs $60.4 \%$ endoscopic) and nonstented groups (88.8\% open vs $69.6 \%$ endoscopic).

SVG patency at 6 months was not significantly different between the stented and nonstented groups $(86.7 \%$ vs $90.9 \%$, respectively, $P=.22$ ). In both study groups, patency rates at 6 months were higher when veins were harvested with an open technique $(91.1 \%$ stented and $94.6 \%$ nonstented, $P=.31$ ) compared with an endoscopic surgical technique $(77.4 \%$ stented and $83.3 \%$ nonstented, $P=$.44).

\section{Major Adverse Cardiac and Cerebrovascular Events}

The overall composite MACCE rate at 2 years was $12 \%$ (22 of 183). The all-cause mortality, stroke, and myocardial infarction rates at 2 years were $2.7 \%$ (5 of 183 ), $3.3 \%$ (6 of 183 ), and $2.7 \%$ (5 of 183), respectively. Ischema-driven revascularization was performed in 6\% (11 of 183) of patients. Reinterventions were more frequently driven by ischemia in the nonstented territory, $3.8 \%$ (7 of 183), than in the stented territory, $2.2 \%$ ( 4 of 183 ).

\section{DISCUSSION}

As explained previously, external stenting for SVG is not primarily designed to mitigate early SVG failure but instead to prevent disease progression over the longer term. With respect to its primary and secondary end points, the current VEST III trial reveals that 2 years after CABG, external stenting mitigates SVG disease progression by significantly improving SVG Fitzgibbon patency and reducing diffuse intimal hyperplasia. Another novel observation is that both angiographic and IVUS findings were significantly correlated with changes in SVG MLD.

Our study has a number of methodological strengths: With 184 patients, VEST III is, by far, the largest randomized clinical trial to evaluate the potential benefit of external stenting on SVG disease progression. The study design included the use of individual patients to act as their own control to eliminate patient-related factors that could potentially influence SVG disease. The successful avoidance of selection bias could influence the balance of baseline grafting parameters by postponing randomization of vein grafts to the external stent until completion of all distal anastomoses. The use of several imaging modalities at different time points provides deeper insights into SVG disease mechanisms, enabling accurate mapping of the different failure modes of SVGs over time.

The importance of trying to mitigate progression of vein graft disease development is underpinned by the landmark 
publication of Fitzgibbon and colleagues,${ }^{18}$ demonstrating that SVGs undergo progressive remodeling, resulting in lumen irregularities and eventual SVG occlusion. At 5, 10 , and 15 years, occlusion rates were $25 \%, 40 \%$, and $50 \%$, respectively; of the remaining nonoccluded SVGs and perfect patency (Fitzgibbon I) rates were 52\%, 23\%, and $19 \%$, respectively. In addition, 5 and 15 years after CABG, $42 \%$ and $44 \%$ of the Fitzgibbon II and III SVGs, respectively, developed high profile lesions with more than $50 \%$ lumen stenosis. ${ }^{18}$

The prognostic value of FPS was demonstrated in the longitudinal studies by Fitzgibbon and colleagues, ${ }^{21}$ which found a direct correlation between FPS and late SVG occlusion. Some $28 \%$ of SVGs with FPS II or III 1 year postCABG were occluded at 5 years compared with only $10 \%$ of those with FPS I $(P<.0005)$. This correlation between lumen irregularities and SVG occlusion was also demonstrated over a longer follow-up period with $39 \%$ of irregular SVGs at 5 years occluded 10 years after CABG compared with only $20 \%$ of the perfectly patent SVGs $(P<.001) .{ }^{20}$ In addition, there was a significant difference in late occlusion rates between FPS II and III, with the latter showing an approximately 3 times higher occlusion rate. $^{20,21}$

Imaging-derived correlates of restenosis propensity, such as MLD and late lumen loss, are powerful efficacy end points that provide additional trend data in patients who have not (yet) developed a major clinical adverse event. ${ }^{22}$ Indeed, similar angiographic measurements have been used to assess other potentially therapeutic treatments such as lipid-lowering agents, as in the POST-CABG TRIAL. ${ }^{22}$ Similar to the MLD differences according to the Fitzgibbon classification groups observed in our study, in the POST-CABG TRIAL, clinically significant reduction in MLD was predefined as a reduction of more than $0.6 \mathrm{~mm}$ in MLD compared with baseline. At 5 to 16 years after CABG, MLD deterioration was found to be significantly lower with the aggressive use of lipid-lowering agents, but this reduction also correlated well with an improved SVG patency rate. ${ }^{22,23}$

In the current trial, the ability of the external stent to significantly reduce diffuse intimal hyperplasia over the entire length of 96 SVG compares well with the findings in the CASCADE trial in which a combination of clopidogrel and aspirin resulted in a insignificant decrease of $7 \%$ in intimal hyperplasia in a more limited examination of the proximal segment of 91 SVGs. ${ }^{24}$ The within-patient control design in VEST III and the fact that all patients in the trial received statins and aspirin strongly suggest that the beneficial effects of external stenting with regard to the mitigation of intimal hyperplasia and the promotion of lumen uniformity were adjunctive to any effect of the medical therapy. In addition, a novel finding in our study was that uniform (Fitzgibbon I) grafts in the nonstented group still showed significantly more intimal hyperplasia than the stented uniform grafts.

The majority of SVG occlusions $(68.4 \%)$ occurred during the first 6 months. These early failures are usually due to technical errors, SVG trauma during harvesting, poorquality conduit, or poor coronary runoff rather than the development of intimal hyperplasia. ${ }^{2,3}$ In the current study, the use of an endoscopic vein harvesting $(\mathrm{EVH})$ technique in some of the study centers seemed to contribute to early vein graft failure. Although EVH was used in only $31.1 \%$ of the cases overall, it was associated with $63.3 \%$ and $58.3 \%$ of the total SVG occlusions in the stented and nonstented groups, respectively. Although EVH may be associated with higher SVG failure rates, ${ }^{25}$ recent data also suggest that the quality of the conduit is highly dependent on the experience of the harvester. ${ }^{26}$ In our trial, EVH experience was not mandated, and differences were observed in EVH experience and SVG patency between centers that used this technique.

\section{Study Limitations}

In contrast to routine clinical follow-up, maintaining patient enthusiasm for and acceptance of repeat angiography is a well-recognized difficulty in prospective trials as previously documented in the ROOBY trial (overall retention rate of $62 \%$ at 1 year), PREVENT IV (overall retention rate of $73 \%$ at 18 months), and CASCADE trial (overall retention rate of $79 \%$ at 1 year). ${ }^{22,27,28}$ Taking into account the longer duration of follow-up of our study and that most of the patients had also undergone CT angiography at 6 months, VEST III compares favorably to previous studies as at 2 years, with $70 \%$ of the overall cohort and $80 \%$ of eligible patients undergoing protocol-driven angiography.

The VEST III sample size remains relatively small $(n=184)$, and the currently reported duration of followup is limited. Furthermore, although the within-patient randomization design is essential to eliminate other patient-related factors that can affect vein graft disease, it cannot currently address the question whether the observed reduction in vein graft disease progression with external stenting will ultimately lead to improved patency and consequently anticipated clinical benefits.

\section{CONCLUSIONS}

Two years after CABG, external stenting of saphenous grafts leads to improved Fitzgibbon patency and significantly reduces SVG disease progression by reducing both the volume and the thickness of intimal hyperplasia. Whether this stabilization of the SVG wall with an external stent will ultimately lead to a reduction in vein graft failure and improved clinical benefits to the patient is not yet known and mandates longer-term follow-up. 


\section{Conflict of Interest Statement}

D.P.T. has received research funding and speaking and traveling fees from Vascular Graft Solutions, and has share options with Vascular Graft Solutions. M.N.B. has received speaking fees from Vascular Graft Solutions for reporting the Blackpool experience with VEST. L.L. reports grants from Vascular Graft Solutions during the conduct of the study. M.B. received financial support from Vascular Graft Solutions for the hospital research and development department in connection with the study. S.S. reports grants, personal fees, and other support from Vascular Graft Solutions. I.F. has received proctoring fees from Vascular Graft Solutions. All other authors reported no conflicts of interest.

The Journal policy requires editors and reviewers to disclose conflicts of interest and to decline handling or reviewing manuscripts for which they may have a conflict of interest. The editors and reviewers of this article have no conflicts of interest.

The authors thank Dr Yuliya Vengrenyuk, Director of the Intravascular Imaging Core Laboratory at the Icahn School of Medicine at Mount Sinai Cardiovascular Institute, for developing the analysis methodology used in this study and performing the angiographic and IVUS data analyses.

\section{References}

1. Schwann TA, Tatoulis J, Puskas J, Bonnell M, Taggart DP, Kurlansky P, et al. Worldwide trends in multi-arterial coronary artery bypass grafting surgery 2004-2014: a tale of 2 continents. Semin Thorac Cardiovasc Surg. 2017;29: 273-80.

2. Harskamp RE, Lopes RD, Baisden CE, de Winter RJ, Alexander JH. Saphenous vein graft failure after coronary artery bypass surgery: pathophysiology, management, and future directions. Ann Surg. 2013;257:824-33.

3. Motwani JG, Topol EJ. Aortocoronary saphenous vein graft disease: pathogenesis, predisposition, and prevention. Circulation. 1998;97:916-31.

4. Owens CD. Adaptive changes in autogenous vein grafts for arterial reconstruction: clinical implications. J Vasc Surg. 2010;51:736-46.

5. Une D, Kulik A, Voisine P, Le May M, Ruel M. Correlates of saphenous vein graft hyperplasia and occlusion 1 year after coronary artery bypass grafting: analysis from the CASCADE randomized trial. Circulation. 2013;128:S213-8.

6. Samano N, Geijer H, Liden M, Fremes S, Bodin L, Souza D. The no-touch saphenous vein for coronary artery bypass grafting maintains a patency, after 16 years, comparable to the left internal thoracic artery: a randomized trial. J Thorac Cardiovasc Surg. 2015; 150:880-8.

7. Kim MS, Hwang HY, Kim JS, Oh SJ, Jang MJ, Kim KB. Saphenous vein versus right internal thoracic artery as a Y-composite graft: five-year angiographic and clinical results of a randomized trial. J Thorac Cardiovasc Surg. 2018;156: 1424-33.e1.

8. Parsonnet V, Lari AA, Shah IH. New stent for support of veins in arterial grafts. Arch Surg. 1963;87:696.

9. Hu J, Wan S. External support in preventing vein graft failure. Asian Cardiovasc Thorac Ann. 2012;20:615-22.

10. Murphy GJ, Newby AC, Jeremy JY, Baumbach A, Angelini GD. A randomized trial of an external Dacron sheath for the prevention of vein graft disease: The Extent study. J Thorac Cardiovasc Surg. 2007;134:504-5.

11. Schoettler J, Jussli-Melchers J, Grothusen C, Stracke L, Schoeneich F, Stohn S, et al. Highly flexible nitinol mesh to encase aortocoronary saphenous vein grafts: first clinical experiences and angiographic results nine months postoperatively. Interact Cardiovasc Thorac Surg. 2011;13:396-400.

12. Taggart DP, Amin S, Djordjevic J, Oikonomou EK, Thomas S, Kampoli AM, et al. A prospective study of external stenting of saphenous vein grafts to the right coronary artery: the VEST II study. Eur J Cardiothorac Surg. 2017;51: 952-8.

13. Friedrich I, Donovan J, Kraiker P, Fassbinder R, Hauptmann KE, Paraforos A. External stenting of vein grafts is safe and effective: single-center report from the multicenter randomized VEST III Trial. Thorac Cardiovasc Surg. 2018;66: S1-110.

14. Taggart DP, Ben Gal Y, Lees B, Patel N, Webb C, Rehman SM, et al. A randomized trial of external stenting for saphenous vein grafts in coronary artery bypass grafting. Ann Thorac Surg. 2015;99:2039-45.

15. Webb CM, Orion E, Taggart DP, Channon KM, Di Mario C. OCT imaging of aorto-coronary vein graft pathology modified by external stenting: 1-year postsurgery. Eur Heart J Cardiovasc Imaging. 2016;17:1290-5.

16. Meirson T, Orion E, Di Mario C, Webb C, Patel N, Channon KM, et al. Flow patterns in externally stented saphenous vein grafts and development of intimal hyperplasia. J Thorac Cardiovasc Surg. 2015;150:871-9.

17. Taggart DP, Webb CM, Desouza A, Yadav R, Channon KM, De Robertis F, et al Long-term performance of an external stent for saphenous vein grafts: the VEST IV trial. J Cardiothorac Surg. 2018;13:117.

18. Fitzgibbon GM, Kafka HP, Leach AJ, Keon WJ, Hooper D, Burton JR. Coronary bypass graft fate and patient outcome: angiographic follow-up of 5,065 grafts related to survival and reoperation in 1,388 patients during 25 years. $J$ Am Coll Cardiol. 1996;28:616-26.

19. Mintz GS, Nissen SE, Anderson WD, Baily SR, Erbel R, Fitzgerald PJ, et al American College of Cardiology Clinical Expert Consensus Document on standards for acquisition, measurement and reporting of intravascular ultrasound studies (IVUS). A report of the American College of Cardiology Task Force on clinical expert consensus documents. J Am Coll Cardiol. 2001;37: 1478-92.

20. FitzGibbon GM, Leach AJ, Kafka HP, Keon WJ. Coronary bypass graft fate: long-term angiographic study. J Am Coll Cardiol. 1991;17:1075-80.

21. FitzGibbon GM, Leach AJ, Keon WJ, Burton JR, Kafka HP. Coronary bypass graft fate. Angiographic study of 1,179 vein grafts early, one year, and five years after operation. J Thorac Cardiovasc Surg. 1986;91:773-8.

22. Post Coronary Artery Bypass Graft Trial Investigators. The effect of aggressive lowering of low-density lipoprotein cholesterol levels and low-dose anticoagulation on obstructive changes in saphenous-vein coronary-artery bypass grafts. $N$ Engl J Med. 1997;336:153-62. Erratum in: N Engl J Med. 1997;337:1859.

23. Campeau L, Hunninghake DB, Knatterud GL, White CW, Domanski M Forman SA, et al. Aggressive cholesterol lowering delays saphenous vein graft atherosclerosis in women, the elderly, and patients with associated risk factors. NHLBI post coronary artery bypass graft clinical trial. Post CABG Trial Investigators. Circulation. 1999;99:3241-7.

24. Kulik A, Le May MR, Voisine P, Tardif JC, Delarochelliere R, Naidoo S, et al Aspirin plus clopidogrel versus aspirin alone after coronary artery bypass grafting: the Clopidogrel After Surgery for Coronary Artery Disease (CASCADE) Trial. Circulation. 2010;122:2680-7.

25. Li G, Zhang Y, Wu Z, Liu Z, Zheng J. Mid-term and long-term outcomes of endoscopic versus open vein harvesting for coronary artery bypass: a systematic review and meta-analysis. Int J Surg. 2019;72:167-73.

26. Krishnamoorthy B, Critchley WR, Venkateswaran RV, Barnard J, Caress A, Fildes JE, et al. A comprehensive review on learning curve associated problems in endoscopic vein harvesting and the requirement for a standardised training programme. J Cardiothorac Surg. 2016;11:45.

27. Hattler B, Messenger JC, Shroyer AL, Collins JF, Haugen SJ, Garcia JA, et al; Veterans Affairs Randomized On/Off Bypass (ROOBY) Study Group. Off-Pump coronary artery bypass surgery is associated with worse arterial and saphenous vein graft patency and less effective revascularization: results from the Veterans Affairs Randomized On/Off Bypass (ROOBY) trial. Circulation. 2012;125:2827-35.

28. Alexander JH, Hafley G, Harrington RA, Peterson ED, Ferguson TB Jr, Lorenz TJ, et al; PREVENT IV Investigators. Efficacy and safety of edifoligide, an E2F transcription factor decoy, for prevention of vein graft failure following coronary artery bypass graft surgery. JAMA. 2005;294:2446-54.

Key Words: CABG, external bypass stent, Fitzgibbon patency, intimal hyperplasia, long-term patency, venous grafts 


\section{APPENDIX E1: STATISTICAL MODEL SPECIFICATIONS}

Details on the 3 statistical methodologies used in the study:

1. Ordinal multinomial regression that was used for the ordinal Fitzgibbon score

2. Logistic regression that was used for all binary variables (Success/Failure)

3. Linear (mixed model) regression that was used for all continuous variables (IH parameters).

\section{Ordinal Multinomial Regression (Primary Analysis)}

The primary end point was analyzed using proportional odds ordinal multinomial regression, with random intercept (defined per subject). In this model, we estimated the following probabilities:

1. Probability of having Fitzgibbon 1 versus Fitzgibbon 2 and 3

2. Probability of having Fitzgibbon 1 and 2 versus Fitzgibbon 3

For each probability, a separate model was fit, where the intercepts are different, but the group coefficient is the same. In other words, this model assumes that though the overall odds of any event can differ, the effect of the graft group (VEST/control) on the odds of an event occurring in every subsequent category is the same for every category.

The model is:

logit(Prob.Fitz 1 vs Fitz $2 \& 3)=\left(\beta_{01}+\delta\right)+\beta_{1} \mathrm{I}\{$ Group $=V E S T\}+\varepsilon$

logit $($ Prob.Fitz $1 \& 2$ vs Fitz 3$)=\left(\beta_{02}+\delta\right)+\beta_{1} \mathrm{I}\{$ Group $=V E S T\}+\varepsilon$

In this logistic regression, intercepts represent the rate of Fitzgibbon 1 and Fitzgibbon 1 and 2 in the control group (after anti-logit transformation), whereas the group coefficient represents the odds ratio.

For convenience, we provide the full output.

\begin{tabular}{lcc}
\hline Covariance parameter & Estimate & Standard error \\
\hline$\delta^{2}$ & 1.3672 & 0.8783 \\
\hline
\end{tabular}

\begin{tabular}{lcccccc}
\hline \multicolumn{1}{c}{ Effect } & Estimate & error & DF & value & $\begin{array}{c}\text { Pr }> \\
|\mathbf{t}|\end{array}$ & $\begin{array}{c}\text { 95\% } \\
\text { CIs }\end{array}$ \\
\hline$\beta_{01}$ & 0.2135 & 0.2413 & 123 & 0.88 & 0.3780 & \\
$\beta_{02}$ & 2.6437 & 0.4056 & 123 & 6.52 & $<0.0001$ & \\
$\beta_{1}$ (VEST) & 0.7018 & 0.3209 & 93 & 2.19 & 0.0312 & $(0.0728-1.3308)$ \\
\hline
\end{tabular}

The odds ratio, is then, given by

odds ratio $=\exp (0.7018)=2.017,95 \%$ CI $(1.07-3.82)$.

\section{Logistic Regression (Vein Graft Occlusion/Patency)}

Analysis of binary variables was done using logistic regression with random by-subject intercept.

$$
\operatorname{logit}(P)=\left(\beta_{01}+\delta\right)+\beta_{1} I\{\text { Group }=V E S T\}+\varepsilon
$$

In this logistic regression, intercept represents the rate of successes in the control group (after anti-logit transformation), whereas the group coefficient represents the odds ratio. Both quantities are reported in Table 4. The only element that was not reported in Table 4 (which is typically not reported) is the variance between by-subjects intercepts.

For convenience we provide the full output.

\begin{tabular}{lcc}
\hline Covariance parameter & Estimate & Standard error \\
\hline$\delta^{2}$ & 0.8246 & 0.4410 \\
\hline
\end{tabular}

\begin{tabular}{lrrrrrr}
\hline \multicolumn{1}{c}{ Effect } & Estimate & error & DF & $\begin{array}{c}\text { t } \\
\text { value }\end{array}$ & $\begin{array}{c}\text { Pr }> \\
|\mathbf{t}|\end{array}$ & $\begin{array}{c}\mathbf{9 5} \% \\
\text { CIs }\end{array}$ \\
\hline$\beta_{01}$ & -1.5655 & 0.2421 & 138 & -6.47 & $<.0001$ & \\
$\beta_{1}($ VEST $)$ & 0.2453 & 0.3109 & 133 & 0.79 & 0.4315 & $(-0.36,0.85)$ \\
\hline
\end{tabular}

The odds ratio, is then, given by

odds ratio $=\exp (0.2453)=1.28,95 \%$ CI $(0.69-2.36)$.

\section{Linear (Mixed Model) Regression (IH Area,} Thickness, Average Lumen Diameter)

Analysis of continuous variables was done using mixed linear regression with random by-subject intercept.

$$
\text { IHParameter }=\left(\beta_{01}+\delta\right)+\beta_{1} I\{\text { Group }=\text { VEST }\}+\varepsilon
$$

Where $\delta$ is the standard deviation between the subjects' intercepts and $\varepsilon$ is the residual standard deviation.

In this linear regression, intercept represents the average value of the examined parameter in the control group, whereas the group coefficient represents the difference between the groups. Table 4 reports only the differences (group coefficients). Table 5 reports both coefficients.

For convenience, we provide the full output. 


\begin{tabular}{|c|c|c|c|}
\hline Dependent variable & $\begin{array}{l}\text { Covariance } \\
\text { parameter }\end{array}$ & Estimate & $\begin{array}{c}\text { Standard } \\
\text { error }\end{array}$ \\
\hline \multirow[t]{2}{*}{ IH area } & $\delta^{2}$ & 0.8256 & 0.2706 \\
\hline & $\varepsilon^{2}$ & 0.8624 & 0.1806 \\
\hline \multirow[t]{2}{*}{ IH thickness } & $\delta^{2}$ & 0.004720 & 0.001680 \\
\hline & $\varepsilon^{2}$ & 0.005837 & 0.001226 \\
\hline \multirow[t]{2}{*}{ Average lumen diameter } & $\delta^{2}$ & 0.1743 & 0.06888 \\
\hline & $\varepsilon^{2}$ & 0.2551 & 0.05421 \\
\hline \multirow[t]{2}{*}{ IH area Fitzgibbon I only } & $\delta^{2}$ & 0.7034 & 0.2705 \\
\hline & $\varepsilon^{2}$ & 0.4982 & 0.1629 \\
\hline \multirow[t]{2}{*}{ IH thickness Fitzgibbon I only } & $\delta^{2}$ & 0.002407 & 0.001629 \\
\hline & $\varepsilon^{2}$ & 0.003933 & 0.001362 \\
\hline \multirow[t]{2}{*}{ Average lumen diameter Fitzgibbon I only } & $\delta^{2}$ & 0.1818 & 0.08083 \\
\hline & $\varepsilon^{2}$ & 0.2202 & 0.06424 \\
\hline
\end{tabular}

\begin{tabular}{lcccrrrr}
\hline \multicolumn{1}{c}{ Dependent variable } & Effect & Estimate & Standard error & $\mathbf{9 5} \%$ CI & DF & t value & $\boldsymbol{P}$ value \\
\hline IH area & $\beta_{01}$ & 3.9627 & 0.1893 & & 50 & 20.93 & $<.0001$ \\
& $\beta_{1}($ VEST) & -0.8962 & 0.1927 & $(-1.2844,-0.5079)$ & 44 & -4.65 & $<.0001$ \\
IH thickness & $\beta_{01}$ & 0.3389 & 0.01500 & & 50 & 22.59 & $<.0001$ \\
& $\beta_{1}($ VEST) & -0.08102 & 0.01583 & $(-0.1129,-0.0491)$ & 44 & -5.12 & $<.0001$ \\
Average lumen diameter & $\beta_{01}$ & 3.3350 & 0.09584 & & 50 & 34.80 & $<.0001$ \\
& $\beta_{1}($ VEST) & 0.1723 & 0.1045 & $(-0.0383,0.3830)$ & 44 & 1.65 & .1063 \\
IH area Fitzgibbon I only & $\beta_{01}$ & 3.7981 & 0.2037 & & 42 & 18.64 & $<.0001$ \\
& $\beta_{1}($ VEST) & -0.9879 & 0.2008 & $(-1.4067,-0.5692)$ & 20 & -4.92 & $<.0001$ \\
IH thickness Fitzgibbon I only & $\beta_{01}$ & 0.3084 & 0.01547 & & 42 & 19.94 & $<.0001$ \\
& $\beta_{1}($ VEST) & -0.07590 & 0.01718 & $(-0.1117,-0.04008)$ & 20 & -4.42 & .0003 \\
Average lumen diameter Fitzgibbon I only & $\beta_{01}$ & 3.6093 & 0.1216 & & 42 & 29.69 & $<.0001$ \\
& $\beta_{1}($ VEST) & -0.04893 & 0.1302 & $(-0.3205,0.2227)$ & 20 & -0.38 & .7111 \\
\hline
\end{tabular}

$C I$, Confidence interval; $D F$, degrees of freedom; $I H$, intimal hyperplasia; $V E S T$, venous external stent. 